\title{
Clinical Implication of ST Segment Depression in aVR \& aVL in Patients with Acute Inferior Wall Myocardial Infarction
}

\author{
Ravi Sahi', Jian Sun ${ }^{*}$, Rajesh Kumar Shah ${ }^{2}$, Madhu Gupta1, Bhabuk Sharma Majagaiya² \\ ${ }^{1}$ Department of Internal Medicine (Cardiology), Norman Bethune of College of Medicine, The First Hospital of \\ Jilin University, Changchun, China \\ ${ }^{2}$ Department of Pediatrics, Norman Bethune of College of Medicine, The First Hospital of Jilin University, \\ Changchun, China \\ Email: sunjianjlu@outlook.com
}

Received 5 August 2015; accepted 25 September 2015; published 28 September 2015

Copyright $(02015$ by authors and Scientific Research Publishing Inc.

This work is licensed under the Creative Commons Attribution International License (CC BY).

http://creativecommons.org/licenses/by/4.0/

(c) () Open Access

\section{Abstract}

Objectives: The aim of the study was to assess the role of ST segment depression in the limb leads aVR and aVL for the diagnosis of acute posterior wall infarction and the identification of infarct related artery (IRA) in patients with acute inferior wall MI. Methods: In 159 patients with I-STEMI, $127(80 \%)$ had RCA occlusion and $32(20 \%)$ had LCX occlusion. In the ECG algorithms, RCA occlusion was indicated by ST depression in lead aVL higher than lead aVR and no ST depression in lead aVL and aVR. LCX occlusion was indicated by ST depression in lead aVR higher than or equal to lead aVL and no ST depression in aVL and aVR. Results: The sensitivity, specificity, positive and negative predictive values of these algorithms were high $(98 \%, 82 \%, 92 \%$ and $95 \%$ for RCA occlusion and $83 \%, 98 \%, 95 \%$ and $92 \%$ for LCX occlusion). Conclusion: The ECG algorithms can reliably identify the culprit artery in I-STEMI. ST segment depression in limb leads aVR and aVL with avR $\geq$ aVL helps to diagnose left circumflex artery as a culprit IRA in an acute inferior wall MI.

\section{Keywords}

Inferior Leads, Infarct Related Artery, ST Elevation Myocardial Infarction, ST Depression, Left Circumflex Artery, Right Coronary Artery

\section{Introduction}

With no doubt, the electrocardiogram (ECG) is the most useful, feasible, cheap and universally available tool for *Corresponding author.

How to cite this paper: Sahi, R., Sun, J., Shah, R.K., Gupta, M. and Majagaiya, B.S. (2015) Clinical Implication of ST Segment Depression in aVR \& aVL in Patients with Acute Inferior Wall Myocardial Infarction. World Journal of Cardiovascular Diseases, 5, 278-285. http://dx.doi.org/10.4236/wjcd.2015.59031 
the initial evaluation, early risk stratification, triage, and guidance of therapy in patients with a suspicion of an acute ischemic event [1]. To predict the culprit artery in Inferior wall STEMI can be challenging because of the variable dominance of RCA and LCX among patients. ECG helps to predict the culprit artery and locate the lesion within the infarct related artery (IRA), thus providing clinically important information to augment clinical decision making and tailor reperfusion therapy [2] [3]. Of the electrocardiographic leads, aVR has traditionally received less attention in clinical evaluation of the ECG [4]. ST segment changes in lead aVR are usually ignored in ECG analysis [5] [6]. Except this lead, all other leads in ECG analysis are considered for recognition of MI and localization of STEMI [7]. The aim of our study was to assess the ST segment depression in limb leads $\mathrm{aVR}$ and $\mathrm{aVL}$ for the identification of IRA and the diagnosis of inferior wall MI. We also dealt with the relation of ratio of ST elevation in lead II and lead III to assess the culprit IRA for the patient with inferior wall MI.

\section{Methods}

It was a prospective cohort study from January 2014 to January 2015. Altogether, the data of 368 patients having an acute inferior wall MI and admitted in the cardiovascular department of the First Hospital of Jilin University were collected. Of them, only 159 patients (male 104 and female 55) were selected for the study as per our inclusion criteria. The inclusion criteria were: chest pain lasting for more than 30 minutes before hospital admission, elevation of troponin I $(>0.01 \mathrm{ng} / \mathrm{ml})$, creatinine kinase (CK-MB) greater than twice the upper limit of normal range (normal: $0-3.5 \mathrm{ng} / \mathrm{ml}$ ), and the ECG showing ST segment elevation $>0.1 \mathrm{mV}(1 \mathrm{~mm})$ in at least 2 of 3 the inferior leads (II, III and aVF). The exclusion criteria were: previous history of acute myocardial infarction, coronary artery bypass surgery or percutaneous coronary intervention prior to current hospitalization, evidence of recent left bundle branch block or left ventricular hypertrophy in ECG, and significant stenosis in both LCX and RCA or triple vessel disease so that a single infarct related artery could not be defined.

Electrocardiography. ECG was recorded in all patients at a paper speed of $25 \mathrm{~mm} / \mathrm{s}$ and voltage of 10 $\mathrm{mm} / \mathrm{mv}$. For inferior STEMI, the inclusion criteria are ST elevation $>0.1 \mathrm{mV}$ in at least two of three inferior leads (II, III and aVF). In addition, standard 12 leads ECG were recorded for the study. The ST segment change was measured from the " $\mathrm{J}$ " point. The electrocardiologists were blinded to the clinical data.

Coronary angiography. In our study, coronary angiography was performed on all the subjects. The coronary angiography was then compared with ECG findings of inferior leads. The angiogram were also analyzed by the cardiologist who performed them other than who interpreted the ECG. Total occlusion or critical stenosis $>70 \%$ in one of the coronary arteries was considered to be significant coronary lesion. All the patients underwent PCI following coronary angiography.

Division of patients. Patients were divided into three groups according to the presence or absence of ST depression $(>0.1 \mathrm{mV})$ in limb leads aVR and aVL on ECG. The first Group was the patient group without ST depression in limb leads aVR and aVL whereas other two Groups were the patient group having ST depression in limb leads $\mathrm{aVR}$ and $\mathrm{aVL}$ i.e ( $\mathrm{aVL}>\mathrm{aVR}$ and $\mathrm{aVR} \geq \mathrm{aVL})$.

Data collection tool. The contents of the intended queries were written sequentially and data were collected and filled in the respective columns.

Statical analysis. All tests of significance were 2 tailed and p values of $<0.05$ was considered as statistically significant. All the statistical analysis were performed using the SPSS, version 9.0 for windows, statistical package.

Results: ST elevation in leads II, III and aVF with ST depression in lead aVR and aVL was more common in male than in female ( $72 \%$ vs $28 \%$ ). There were no significant differences between 3 groups in base line clinical characteristics and prevalence risk factors (Table 1). In the ECG of ST elevation in the inferior leads (II, III and aVF), ST elevation in leads III > II was highly associated with ST depression in lead aVL $>$ aVR than with ST depression in lead $\mathrm{aVL} \leq \mathrm{aVR}(98 \%$ vs $22 \%)(\mathrm{p}=<0.0001)$, whereas ST elevation in lead II $>$ III was more associated with ST depression in lead $\mathrm{aVL} \leq \mathrm{aVR}$ than $\mathrm{aVL}>\mathrm{aVR}(78 \%$ vs $2 \%)(\mathrm{p}=<0.0001)$. There was no significant difference in KILIP I and ejection fraction between the three groups (Table 2). Among 69 patients with ST depression in leads aVR and aVL, the infarct related artery was right coronary artery in 49 patients (71\%) and left circumflex artery in 20 (29\%). In No ST depression in leads aVR and aVL and ST depression in lead aVL > aVR were strongly associated with RCA occlusion; 87\% and 98\% respectively. Whereas, ST depression in lead aVL $\leq$ aVR was associated with LCX, 83\% occlusion. TIMI 0 coronary flow was found in 107 patients (67\%). No significant differences were found between three groups regarding TIMI 0 flow score (Table 3). The right coronary artery (RCA) disease was found significantly higher in proportion with ST depression in 
Table 1. Baseline clinical characteristics.

\begin{tabular}{|c|c|c|c|c|}
\hline \multirow[t]{3}{*}{ Variable } & \multirow{2}{*}{$\begin{array}{c}\text { No ST } \downarrow \text { in Lead aVL-aVR } \\
\text { (n: 90) }\end{array}$} & \multicolumn{2}{|c|}{$\underline{\text { ST } \downarrow \text { in Lead aVL-aVR }}$} & \multirow[t]{2}{*}{ p Value } \\
\hline & & $\mathrm{ST} \downarrow$ in Lead aVL $>\mathrm{aVL}$ & $\mathrm{ST} \downarrow$ in Lead $\mathrm{aVL} \leq \mathrm{aVR}$ & \\
\hline & & (n: 46) & (n: 23) & \\
\hline AGE & $59.78 \pm 11.807$ & $58.65 \pm 10.429$ & $59.30 \pm 13.461$ & 0.87 \\
\hline \multirow{2}{*}{ GENDER } & M-54 (60\%) & M-32 (70\%) & M-18 (78\%) & \multirow{2}{*}{0.20} \\
\hline & F-36 (40\%) & F-14 (30\%) & F-5 (22\%) & \\
\hline SMOKING & $63(70 \%)$ & 37 (80\%) & $14(61 \%)$ & 0.20 \\
\hline HYPERTENSION & $44(49 \%)$ & 17 (37\%) & $13(57 \%)$ & 0.24 \\
\hline DIABETES MELLITUS & $22(24 \%)$ & 7 (15\%) & $4(17 \%)$ & 0.41 \\
\hline DYSLIPIDEMIA & 38 (42\%) & 15 (33\%) & 12 (52\%) & 0.27 \\
\hline
\end{tabular}

$\mathrm{p}<0.05$ is clinically significant.

Table 2. Clinical, biochemical, ECG and ECHO.

\begin{tabular}{|c|c|c|c|c|}
\hline \multirow[t]{3}{*}{ Variable } & \multirow{2}{*}{$\begin{array}{c}\text { No ST } \downarrow \text { in Lead aVL-aVR } \\
\text { (n: 90) }\end{array}$} & \multicolumn{2}{|c|}{$\underline{\text { ST } \downarrow \text { in Lead aVL-aVR }}$} & \multirow[t]{2}{*}{ p Value } \\
\hline & & $\mathrm{ST} \downarrow$ in Lead $\mathrm{aVL}>\mathrm{aVR}$ & $\mathrm{ST} \downarrow$ in Lead $\mathrm{aVL} \leq \mathrm{aVR}$ & \\
\hline & & (n: 46) & (n: 23) & \\
\hline KILIP 1 & 82 (91\%) & 42 (91\%) & 19 (83\%) & 0.45 \\
\hline \multicolumn{5}{|l|}{$\mathrm{ST} \uparrow$ in } \\
\hline $\mathrm{II} \geq \mathrm{III}$ & $13(14 \%)$ & $1(2 \%)$ & $18(78 \%)$ & $<0.0001^{* * *}$ \\
\hline III $>$ II & 77 (86\%) & 45 (98\%) & $5(22 \%)$ & $<0.0001^{* * *}$ \\
\hline Ejection Fraction (\%) & $55.08 \pm 5.098$ & $55.30 \pm 6.622$ & $54.17 \pm 5.262$ & 0.72 \\
\hline Troponin I (ng /mL) & $23.89 \pm 49.84$ & $32.27 \pm 60.37$ & $54.22 \pm 64.88$ & 0.07 \\
\hline
\end{tabular}

${ }^{*} \mathrm{p}<0.05$ clinically significant, ${ }^{* *} \mathrm{p}<0.005$ highly significant, ${ }^{* * *} \mathrm{p}<0.0005$ very highly significant.

Table 3. Coronary angiography (CAG).

\begin{tabular}{|c|c|c|c|c|}
\hline \multirow[t]{3}{*}{ Variable } & \multirow{2}{*}{$\begin{array}{c}\text { No ST } \downarrow \text { in Lead aVL-aVR } \\
\text { (n: 90) }\end{array}$} & \multicolumn{2}{|c|}{ ST $\downarrow$ in Lead aVL-aVR } & \multirow[t]{2}{*}{ p Value } \\
\hline & & $\mathrm{ST} \downarrow$ in Lead aVL $>$ aVR & $\mathrm{ST} \downarrow$ in Lead $\mathrm{aVL} \leq \mathrm{aVR}$ & \\
\hline & & (n: 46) & (n: 23) & \\
\hline RCA & $78(87 \%)$ & 45 (98\%) & $4(17 \%)$ & $<0.0001^{* * *}$ \\
\hline LCX & $12(13 \%)$ & $1(2 \%)$ & 19 (83\%) & $<0.0001^{* * *}$ \\
\hline TIMI 0 & $58(64 \%)$ & $29(63 \%)$ & $20(87 \%)$ & 0.09 \\
\hline
\end{tabular}

RCA: Right coronary artery, LCX: Left circumflex artery.

lead aVL > aVR (n: 45; 98\%) than with ST depression in lead aVL $\leq$ aVR (n: 4; 17\%) (p =< 0.0001), whereas the left circumflex artery (LCX) disease was found very frequently with ST depression in aVL $\leq$ aVR (n: 19; 83\%) than with ST depression in lead aVL > aVR (n: 1; 2\%) $(\mathrm{p}=<0.0001)$.

In our study, out of 159 patients; 57\% (n: 90) had no ST depression in leads aVR and aVL, 43\% (n: 69) patients had ST depression in leads aVR and aVL in relation to ST elevation in the inferior leads (II, III and aVF). Out of 69 patients, 67\% (n: 46) had ST depression in lead aVL > aVR, whereas 33\% (n: 23) had ST depression in lead $\mathrm{aVL} \leq \mathrm{aVR}$. According to coronary angiography findings the sensitivity, specificity and positive predic- 
tive value and negative predictive value of ST depression in lead aVL $>$ aVR to predict right coronary artery (RCA) as a culprit artery are $98 \%, 82 \%, 92 \%$ and $95 \%$ respectively. And, the sensitivity, specificity, positive predictive value and negative predictive value of ST depression in lead aVL $\leq$ aVR to predict left circumflex artery (LCX) as a culprit artery are $83 \%, 98 \%, 95 \%$ and $92 \%$ respectively (Table 4 ).

The ST segment elevation of $\geq 1 \mathrm{~mm}(>0.1 \mathrm{mv})$ in inferior leads II, III and aVF is significant to make the diagnosis of acute inferior wall STEMI. The ratio of ST elevation in leads II and III has a clinical implication to predict the culprit artery. In our study, ST elevation in lead III $\leq$ II was seen in 31 (19\%) patients, and in lead III > II in 128 (81\%) patients. Right coronary artery (RCA) was frequently involved in ECG with ST elevation in lead III > II (n: 127; 99\%) $(\mathrm{p}=<0.0001)$ and left circumflex artery (LCX) in lead III $\leq$ II (n: 29; 94\%) $(\mathrm{p}=<0.0001)$ (Table 5). The sensitivity, specificity, positive predictive value and negative predictive value for ST elevation in lead III $\leq$ II to predict LCX as a culprit artery are $94 \%, 99 \%, 97 \%$ and $98 \%$, respectively, whereas sensitivity, specificity, positive predictive value and negative predictive value for ST elevation in lead III > II to predict RCA as a culprit artery are $99 \%, 94 \%, 98 \%$ and $97 \%$ respectively (Table 6 ).

\section{Discussion}

Abnormalities on the electrocardiogram (ECG) are frequently used to predict the infarct related artery (IRA) in patients with acute myocardial infarction (AMI). Acute myocardial infarction of the inferolateral wall is due to occlusion of the right coronary artery (RCA) or the left circumflex (LCX) coronary artery and the outcome depends on the culprit artery involved [8]. Thus, the presumptive prediction of a culprit artery based on electrocardiography is of clinical importance. Our findings have important clinical implications to predict the infarct related artery (RCA or LCX) by comparing the degree of ST depression in lead aVR with that of lead aVL in inferior wall STEMI.

The few studies have suggested that ST depression in leads aVR and aVL suggests the presence of the left circumflex artery (LCX) occlusion [9] [10]. In our study, among 69 patients with ST depression in leads aVR and aVL, the infarct-related artery was the right coronary artery in 49 patients $(71 \% ; \mathrm{p}=<0.0001)$ and left circumflex artery (LCX) in 20 patients (29\%; $\mathrm{p}=<0.0001)$. The pattern of ST depression in leads aVR and aVL was strongly related to the infarct related artery; that is ST depression in lead aVL $>$ aVR indicated right coronary artery (RCA) occlusion in 45 patients (98\%), with sensitivity and specificity of $98 \%$ and $82 \%$ respectively. Whereas ST depression in lead aVL $\leq$ aVR indicated left circumflex artery (LCX) occlusion in 19 patients (83\%) with sensitivity and specificity of $83 \%$ and $98 \%$ respectively. These findings are better than with the results of Ilkka Tierala et al. [10].

Table 4. According to Coronary angiography; to predict the culprit artery in ST $\downarrow$ in lead aVL-aVR in related to ST $\downarrow$ in lead $\mathrm{aVL}>\mathrm{aVR}$ and ST $\downarrow$ in lead aVL $\leq \mathrm{aVR}$ (RCA or LCX): Sensitivity, specificity, PPV and NPV.

\begin{tabular}{|c|c|c|c|c|c|}
\hline ECG & CAG & Sensitivity & Specificity & PPV & NPV \\
\hline $\mathrm{ST} \downarrow$ in Lead aVL $>$ aVR & RCA & $98 \%$ & $82 \%$ & $92 \%$ & $95 \%$ \\
\hline $\mathrm{ST} \downarrow$ in Lead $\mathrm{aVL} \leq \mathrm{aVR}$ & LCX & $83 \%$ & $98 \%$ & $95 \%$ & $92 \%$ \\
\hline
\end{tabular}

PPV: Positive Predictive Value, NPV: Negative Predictive Value, CAG: Coronary angiography.

Table 5. Clinical significance of ST elevation in inferior leads (II, III and aVF) to predict the culprit artery.

\begin{tabular}{cccc}
\hline Characteristics (n: 159) & II $\geq$ III (n: 31; 19\%) & III > II (n: 128; 81\%) & p Value \\
\hline RCA & $2(6 \%)$ & $127(99 \%)$ & $<0.0001^{* * *}$ \\
LCX & $29(94 \%)$ & $1(1 \%)$ & $<0.0001^{* * *}$ \\
\hline
\end{tabular}

Table 6. To predict culprit artery in II, III and $\alpha$ VF; sensitivity, specificity and positive predictive value and negative predictive value.

\begin{tabular}{|c|c|c|c|c|c|}
\hline ECG & CAG & Sensitivity & Specificity & PPV & NPV \\
\hline $\mathrm{II} \geq \mathrm{III}$ & LCX & $94 \%$ & $99 \%$ & $97 \%$ & $98 \%$ \\
\hline III $>$ II & RCA & $99 \%$ & $94 \%$ & $98 \%$ & $97 \%$ \\
\hline
\end{tabular}


There have been several ECG criteria proposed to identify the IRA in inferior wall STEMI [6] [8] [11]-[19]. However, in the presence of ST depression in leads aVR and aVL in inferior wall AMI, we believe that these simple ECG criteria are useful for predicting the infarct related artery (IRA) in the clinical practice to evaluate the high-risk. The aVL lead faces the high lateral segment of the left ventricular wall and is the only lead that is truly reciprocal to the inferior wall. The aVL lead should depict a decrease in $\mathrm{R}$ wave amplitude and an increase in S wave amplitude. The standard lead III is oriented to the right inferior segment, whereas lead II is oriented principally to the left inferior segment and also to the inferior region of the left lateral part of the superior wall of the ventricle. Consequently, lead III is more influenced by RCA-related AMI and lead II by LCX-related AMI [12] [20] [21]. The purpose of lead aVR was to obtain specific information from the right upper side of the heart, such as the outflow tract of the right ventricle and the basal part of the septum. In practice, however, most electrocardiographers consider lead aVR as giving reciprocal information from the left lateral side, being already covered by the leads aVL, II, V5 and V6. This has been the reason that lead aVR has become largely ignored. ST segment depression in lead aVR has been suggested as a predictor of LCX artery involvement by some of the studies [22]. Nair and Glancy [23] found that quantifying ST depression in lead aVR distinguished a culprit LCX ( $\geq 1 \mathrm{~mm}$ ) from a culprit RCA ( $<1 \mathrm{~mm}$ or no depression), in a small retrospective analysis. However, Baptista et al. [24] found that lead aVR ST depression showed limited use in differentiation between the RCA and the LCX. Sensitivity and specificity to predict the infarct related artery were $33 \%$ and $71 \%$, respectively.

In the present study, 19 patients (83\%) had LCX occlusion with ST depression in lead aVL $\leq \mathrm{aVR}$. The ECG changes during LCX artery occlusion is highly variable because of its anatomical distribution. The LCX supplies blood to the posterior, posterolateral, posteroinferior, or posteroinferolateral myocardium [25]. During LCX occlusion, posterolateral wall involvement is associated with proximal occlusion because this region is supplied, at least in part, by the obtuse marginal branch of the LC artery [15] [25]. When occlusion of the LCX artery more distally, the posterolateral wall will not be involved, and the ST-segment vector will be oriented more inferiorly [25]. Cardiologists should pay more attention to the tracing of lead aVR when interpreting the 12-lead ECG in clinical practice [26]. Thus, when assessing the greater risk area in patients with inferior wall AMI, the clinician should consider the presence of ST segment depression in leads aVR and aVL, which implies a large perfusion area of the left ventricle and the need for aggressive therapeutic strategies to improve myocardial reperfusions. Tierala et al. proposed that in inferior AMI, right coronary artery (RCA) might be the culprit IRA, if the degree of ST elevation in lead III > II and left circumflex artery (LCX) if the ST elevation in lead II $\geq$ III [10]. In our study, we reported that in patients with inferior AMI, the degree of ST elevation in the inferior leads, mainly leads III > II, was significantly greater in right coronary artery (RCA) occlusion than in left circumflex artery occlusion ( $99 \%$ vs $1 \%$ ).

The sensitivity and specificity of ST elevation in III > II for RCA are $99 \%$ and $94 \%$ respectively (p $=<$ 0.0001), whereas the sensitivity and specificity of II $\geq$ III for LCX are $94 \%$ and $99 \%$ respectively. Importantly, ST elevation in lead III $>$ II frequently supported ST depression in lead aVL $>$ aVR than ST depression in lead $\mathrm{aVL} \leq \mathrm{aVR}$ (n: 45; 98\% vs n: 5; 22\%; p =< 0.0001) (Figure 1). However, ST elevation in lead II > III favored ST depression in lead aVL $\leq$ aVR than ST depression in lead aVL $>$ aVR (n: 18; 78\% vs n: $1 ; 2 \% ; p=<0.0001$ ) (Figure 2).

\section{Study Limitations}

The present study had several limitations that need to be considered when interpreting the clinical implications of our findings. This was a small sample size, prospective study in a single center. The study didn't deal in predicting the lesion either proximal or distal coronary occlusion, mega artery involvement. The study lacked the follow-up and complications like reinfarction, post infarction angina, arrhythmias and mortality. The electrocardiographic findings in our study might differ considerably from those patients with previous episodes of myocardial infarction, late presentation. Thus, our findings cannot be generalized to all patients with inferior wall AMI and large-scale studies are needed to confirm the present findings. We do not think that using these ECG criteria should replace angiography, but it would provide earlier identification of the culprit artery.

\section{Conclusion}

In conclusion, ST segment depression in leads aVR and aVL suggests a greater risk area in-patient with acute inferior wall myocardial infarction. The right coronary artery occlusion was most common in ST depression in 


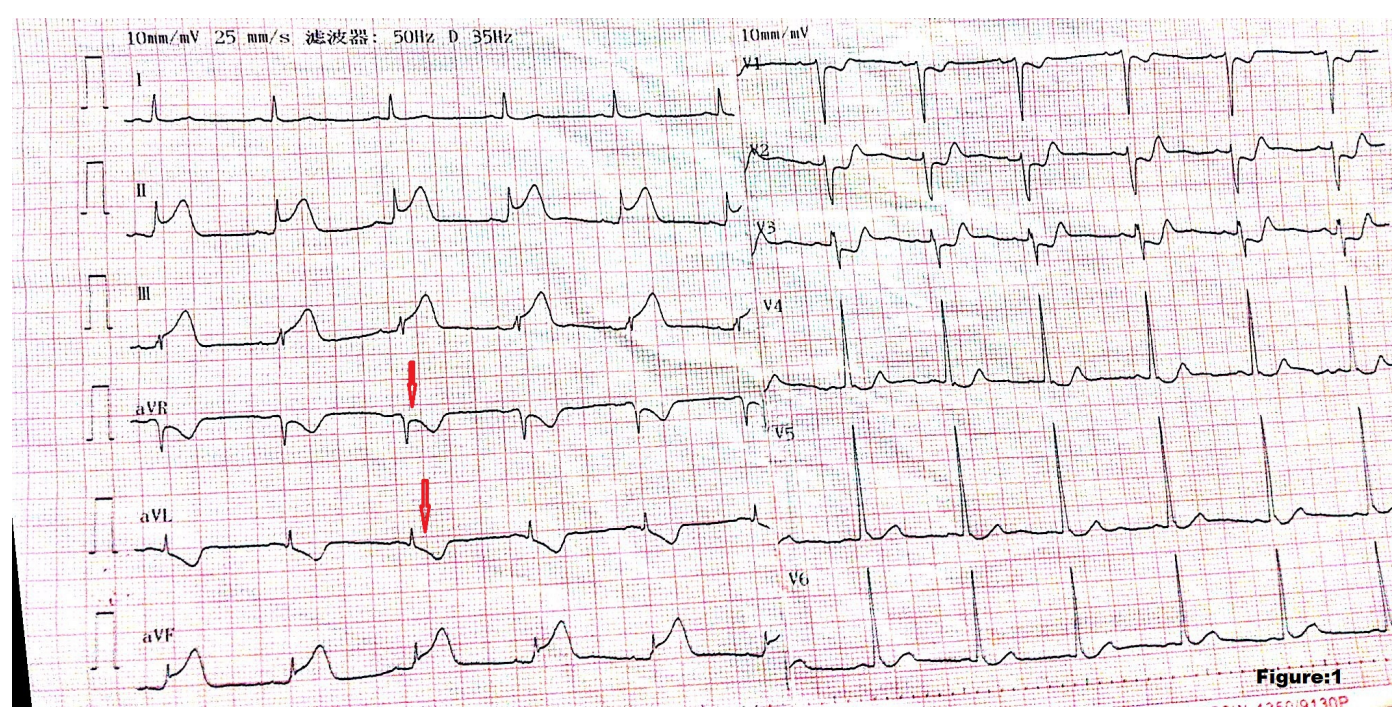

Figure 1. In inferior STEMI with the left circumflex artery as the infarct-related artery; the ST depression may be deeper in lead aVR than in lead aVL with III $\leq$ II.

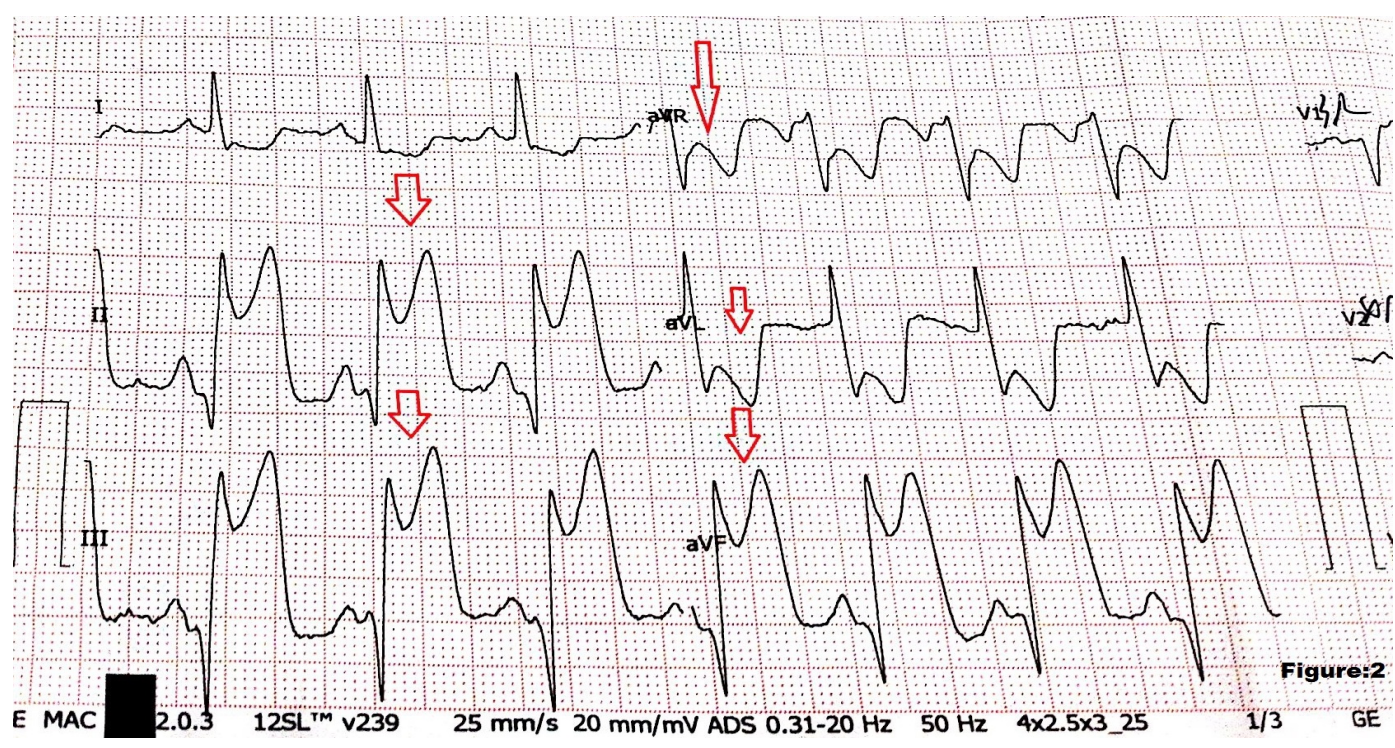

Figure 2. In inferior STEMI with the right coronary artery as the infarct-related artery; the ST depression may be deeper in lead aVL than in lead aVR with III > II.

leads aVL and aVR with ST depression in lead aVL $>$ aVR and the left circumflex artery occlusion in ST depression in leads aVL and aVR with ST depression in lead $\mathrm{aVL} \leq \mathrm{aVR}$. And, while evaluating risk in an acute inferior wall myocardial infarction, we should also look for ST depression in leads aVR and aVL, as it signifies a larger perfusion territory and demands for more aggressive reperfusion therapy.

\section{References}

[1] Sclarovsky, S. (1999) Electrocardiography of Acute Myocardial Ischaemic Syndromes. Martin Dunitz Ltd., London.

[2] Eskola, M.J., Nikus, K.C., Holmvang, L., et al. (2008) Value of the 12-Lead Electrocardiogram to Define the Level of Obstruction in Acute Anterior Wall Myocardial Infarction: Correlation to Coronary Angiography and Clinical Outcome in the DANAMI-2 Trial. International Journal of Cardiology, 131, 378-383. http://dx.doi.org/10.1016/j.ijcard.2007.10.035

[3] Eskola, M.J., Nikus, K.C., Niemela, K.O. and Sclarovsky, S. (2004) How to Use ECG for Decision Support in the Ca- 
theterization Laboratory. Cases with Inferior ST elevation Myocardial Infarction. Journal of Electrocardiology, 37, 257. http://dx.doi.org/10.1016/j.jelectrocard.2004.07.003

[4] George, A., Arumugham, P.S. and Figueredo, V.M. (2010) aVr-The Forgotten Lead. Experimental \& Clinical Cardiology, 15, e36-e44.

[5] Andersen, H.R., Nielsen, D. and Falk, E. (1989) Right Ventricular Infarction: Diagnostic Value of ST Elevation in Lead III Exceeding That of Lead II during Inferior/Posterior Infarction and Comparison with Right-Chest Leads V3R to V7R. American Heart Journal, 117, 82-86. http://dx.doi.org/10.1016/0002-8703(89)90659-5

[6] Chia, B.L., Yip, J.W., Tan, H.C., et al. (2000) Usefulness of ST Elevation II/III Ratio and ST Deviation in Lead I for Identifying the Culprit Artery in Inferior Wall Acute Myocardial Infarction. The American Journal of Cardiology, 86, 341-343. http://dx.doi.org/10.1016/S0002-9149(00)00929-2

[7] Stone, G.W., Petrson, M.A., Lansky, A.J., et al. (2002) Impact of Normalized Myocardial Perfusion after Successful Angioplasty in Acute Myocardial Infarction. Journal of the American College of Cardiology, 39, 591-597. http://dx.doi.org/10.1016/S0735-1097(01)01779-X

[8] Assali, A.R., Sclarovsky, S., Herz, I., Adler, Y., Porter, A., Solodky, A. and Strasberg, B. (1998) Comparison of Patients with Inferior Wall Acute Myocardial Infarction with versus without ST-Segment Elevation in Leads V5 and V6. American Journal of Cardiology, 81, 81-83. http://dx.doi.org/10.1016/S0002-9149(97)00808-4

[9] Kanei, Y., Sharma, J., Diwan, R., et al. (2010) ST-Segment Depression in aVR as a Predictor of Culprit Artery and Infarct size in Acute Inferior Wall ST-Segment Elevation Myocardial Infarction. Journal of Electrocardiology, 43, 132. http://dx.doi.org/10.1016/j.jelectrocard.2009.09.003

[10] Tierala, I., et al. (2009) Predicting the Culprit Artery in Acute ST-Elevation Myocardial Infarction and Introducing a New Algorithm to Predict Infarct-Related Artery in Inferior ST-Elevation Myocardial Infarction: Correlation with Coronary Anatomy in the HAAMU Trial. Journal of Electrocardiology, 42, 120-127. http://dx.doi.org/10.1016/j.jelectrocard.2008.12.009

[11] Zimetbaum, P.J. and Josephson, M.E. (2003) Use of the Electrocardiogram in Acute Myocardial Infarction. New England Journal of Medicine, 348, 933-940. http://dx.doi.org/10.1056/NEJMra022700

[12] Zimetbaum, P., Krishnan, S., Gold, A., Carrozza II, J.P. and Josephson, M. (1998) Usefulness of ST-Segment Elevation in Lead III Exceeding That of Lead II for Identifying the Location of the Totally Occluded Coronary Artery in Inferior Wall Myocardial Infarction. American Journal of Cardiology, 81, 918-919. http://dx.doi.org/10.1016/S0002-9149(98)00013-7

[13] Herz, I., Assali, A.R., Adler, Y., Solodky, A. and Sclarovsky, S. (1997) New Electrocardiographic Criteria for Predicting Either the Right or Left Circumflex Artery as the Culprit Coronary Artery in Inferior Wall Acute Myocardial Infarction. American Journal of Cardiology, 80, 1343-1345. http://dx.doi.org/10.1016/S0002-9149(97)00678-4

[14] Bairey, C.N., Shah, K., Lew, A.S. and Hulse, S. (1987) Electrocardiographic Differentiation of Occlusion of the Left Circumflex versus the Right Coronary Artery as a Cause of Inferior Acute Myocardial Infarction. American Journal of Cardiology, 60, 456-459. http://dx.doi.org/10.1016/0002-9149(87)90285-2

[15] Hasdai, D., Birnbaum, Y., Herz, I., Sclarovsky, S., Mazur, A. and Solodky, A. (1995) ST Segment Depression in Lateral Limb Leads in Inferior Wall Acute Myocardial Infarction: Implications regarding the Culprit Artery and the Site of Obstruction. European Heart Journal, 16, 1549-1553.

[16] Kontos, M.C., Desai, P.V., Jesse, R.L. and Ornato, J.P. (1997) Usefulness of the Admission Electrocardiogram for Identifying the Infarct-Related Artery in Inferior Wall Acute Myocardial Infarction. American Journal of Cardiology, 79, 182-184. http://dx.doi.org/10.1016/S0002-9149(96)00709-6

[17] Kosuge, M., Kimura, K., Ishikawa, T., Hongo, Y., Mochida, Y., Sugiyama, M. and Tochikubo, O. (1998) New Electrocardiographic Criteria for Predicting the Site of Coronary Artery Occlusion in Inferior Wall Acute Myocardial Infarction. American Journal of Cardiology, 82, 1318-1322. http://dx.doi.org/10.1016/S0002-9149(98)00634-1

[18] Zhan, Z.Q., Wang, W., Dang, S.Y., Wang, C.Q., Wang, J.F. and Cao, Z. (2009) Electrocardiographic Characteristics in Angiographically Documented Occlusion of the Dominant Left Circumflex Artery with Acute Inferior Myocardial Infarction: Limitations of ST Elevation III/II Ratio and ST Deviation in Lateral Limb Leads. Journal of Electrocardiology, 42, 432-439. http://dx.doi.org/10.1016/j.jelectrocard.2009.03.015

[19] Wagner, G.S., Macfarlane, P., Wellens, H., Josephson, M., Gorgels, A., Mirvis, D.M., Pahlm, O., Surawicz, B., Kligfield, P., Childers, R., Gettes, L.S., Bailey, J.J., Deal, B.J., Gorgels, A., Hancock, E.W., Kors, J.A., Mason, J.W., Okin, P., Rautaharju, P.M. and van Herpen, G., American Heart Association Electrocardiography and Arrhythmias Committee, Council on Clinical Cardiology, American College of Cardiology Foundation, Heart Rhythm Society (2009) AHA/ACCF/HRS Recommendations for the Standardization and Interpretation of the Electrocardiogram: Part VI: Acute Ischemia/Infarction: A Scientific Statement from the American Heart Association Electrocardiography and Arrhythmias Committee, Council on Clinical Cardiology; the American College of Cardiology Foundation; and the Heart Rhythm Society. Journal of the American College of Cardiology, 53, 1003-1011. 
http://dx.doi.org/10.1016/j.jacc.2008.12.016

[20] Huey, B.L., Beller, G.A., Kaiser, D.L. and Gibson, R.S. (1988) A Comprehensive Analysis of Myocardial Infarction Due to Left Circumflex Artery Occlusion: Comparison with Infarction Due to Right Coronary Artery and Left Anterior Descending Artery Occlusion. Journal of the American College of Cardiology, 12, 1156-1166. http://dx.doi.org/10.1016/0735-1097(88)92594-6

[21] Dunn, R.F., Newman, H.N., Bernstein, L., Harris, P.J., Roubin, G.S., Morris, J. and Kelly, D.T. (1984) The Clinical Features of Isolated Left Circumflex Coronary Artery Disease. Circulation, 69, 477-484. http://dx.doi.org/10.1161/01.CIR.69.3.477

[22] Menown, I.B.A. and Adgey, A.A.J. (2000) Improving the ECG Classification of Inferior and Lateral Myocardial Infarction by Inversion of Lead aVR. Heart, 83, 657-660. http://dx.doi.org/10.1136/heart.83.6.657

[23] Nair, R. and Glancy, D.L. (2002) ECG Discrimination between Right and Left Circumflex Coronary Arterial Occlusion in Patients with Acute Inferior Myocardial Infarction: Value of Old Criteria and Use of Lead aVR. Chest, 122, 134. http://dx.doi.org/10.1378/chest.122.1.134

[24] Baptista, S.B., Farto e Abreu, P., Loureiro, J.R., et al. (2004) Electrocardiographic Identification of the Infarct-Related Artery in Acute Inferior Myocardial Infarction. Revista Portuguesa de Cardiologia, 23, 963-971.

[25] Barnhill III, J.E., Tendera, M., Cade, H., Campbell, W.B. and Smith, R.E. (1989) Depolarization Changes Early in the Course of Myocardial Infarction: Significance of Changes in the Terminal Portion of the QRS Complex. Journal of the American College of Cardiology, 14, 143-149. http://dx.doi.org/10.1016/0735-1097(89)90064-8

[26] Tamura, A. (2014) Significance of Lead aVR in Acute Coronary Syndrome. World Journal of Cardiology, 6, 630-637. http://dx.doi.org/10.4330/wjc.v6.i7.630 